\title{
Role of Right Liver Lobe Diameter/Serum Albumin Ratio in Esophageal Varices Assessment in Cirrhotic Patients
}

\author{
Mohamed Negm Eldin Salem*, Mostafa Abdel Aziz Elhawary*, Mohamed Ghareb Mohamed \\ Shekh roho*, Mohamed Abdel Hamid Bassyoni Khedr**, Sobhi Ramadan Abdallah* \\ Department of Tropical Medicine* and Department of Clinical Pathology**, Faculty of Medicine Al- \\ Azhar University, Cairo, Egypt \\ Corresponding author: Sobhi Ramadan Abdallah, E-mail: sobhi.rmadan@gmail.com
}

\begin{abstract}
Background: Liver cirrhosis is a pathologic condition characterized by fibrosis of the liver parenchyma and evidence of regenerative activity, resulting in portal hypertension. Portal hypertension plays a crucial role in the transition from the pre-clinical to the clinical phase of the disease. Bleeding from ruptured esophagogastric varices is the most severe complication of cirrhosis and is the cause of death in about one third of cirrhotic patients. Cirrhotic patients frequently undergo screening endoscopy for the presence of varices. These recommendations imply a considerable burden of endoscopies and related costs. Objective: the aim of the study was to determine the predictive value of noninvasive parameters (Rt. lobe diameter/ serum albumin ratio) in the prediction of esophageal varices. Subjects and Methods: This study was done on 120 patients divided into four groups: Group A: includes 30 cirrhotic patients with esophageal varices (OVs) grade I to II. Group B: includes 30 cirrhotic patients with OVs grade III to IV. Group C: includes 30 cirrhotic patients without OVs. Group D: includes 30 none cirrhotic patients presented for esophagogastroduodenoscopy (EGD) screening because of other etiologic factors that are not associated with liver cirrhosis. All participants were subjected to clinical examination; laboratory investigations ( $\mathrm{CBC}$, Liver function tests including serum albumin concentration, prothrombin time and concentration, modified Child-Pugh score and abdominal ultrasonography (studying the right lobe and left lobe diameter, the presence of periportal thickening, the splenic longest axis and the presence of ascites and Portal vein diameter, Right liver lobe diameter/albumin ratio were calculated for all patients). Upper endoscopy was done for detection and grading of esophageal varices. Results: This study revealed that The predictors that showed statistically significantly associated with the presence of varices were increased right lobe diameter/Albumin ratio, shrunken Rt. hepatic lobe, splenomegaly, thrombocytopenia, and the more advanced liver disease (according to child class scoring of the patients), the more likely the presence of varices. Conclusion: Right lobe diameter/Albumin ratio is good predictor for the presence and grading of esophageal varices.
\end{abstract}

Keywords: Right Liver Lobe Diameter/Serum Albumin Ratio, Esophageal Varices, Cirrhotic Patients, Esophagogastroduodenoscopy

\section{INTRODUCTION}

Cirrhosis is a pathologic condition characterized by fibrosis of the liver parenchyma and evidence of regenerative activity, resulting in portal hypertension ${ }^{(1)}$.

Esophageal varices are related to portal hypertension which commonly accompanies the presence of liver cirrhosis, with a prevalence that can range from 40 to $80 \%$ in patients with cirrhosis ${ }^{(2)}$. The yearly rate of development of "new" varices is about 5-10\% per year in patients with cirrhosis, and the progression from small to large varices occur in $10 \%$ to $20 \%$ of cases after 1 year. In the 2 years following the first detection of esophageal varices, the risk of variceal bleeding ranges between $20 \%$ to $30 \%$ and results in $25 \%$ to
$50 \%$ mortality within a week of the first bleeding episode ${ }^{(3)}$.

The current recommendations are that all cirrhotic patients should be screened for the presence of varices at the time of initial diagnosis of cirrhosis. Follow-up endoscopy should be performed at 2-3 years intervals in compensated patients with no varices, and at 1-2 years intervals in compensated patients with small varices (4). Although all patients with cirrhosis will eventually develop esophagogastric varices at a given point in time, a variable proportion of un selected cirrhotic patients will not have varices. Therefore, performing endoscopy in all patients to detect varices implies a number of unnecessary 
endoscopies ${ }^{(5)}$. These recommendations imply a considerable burden of endoscopies and related costs; they require that patients repeatedly undergo an unpleasant invasive procedure, even though up to $50 \%$ of them may still not have developed esophageal varices 10 years after the diagnosis of cirrhosis. Therefore, these guidelines might not be ideal for clinical practice ${ }^{(6)}$.

It would be impossible to perform endoscopic examinations at regular interval for all patients with chronic liver disease and it may be more costeffective to routine screening of varices, On the other hand, many patients refuse repeated endoscopies because of discomfort and fear of transmission of infection (7). endoscopic examination is considered an invasive procedure. Moreover, sedation of a cirrhotic patient to perform endoscopy may be hazardous ${ }^{(8)}$. Also, diagnostic upper gastrointestinal endoscopy may contribute to bacterial infections in patients with liver cirrhosis due to associated disruption of the natural barriers ${ }^{(9)}$.

As a consequence, several non-invasive tools have been evaluated as an alternatives to endoscopy, to avoid unnecessary endo-scopy in low-risk patients, and to identify noninvasive factors that may predict the presence of esophageal varices (10)(11)(12). As far as the clinical/laboratory parameters are concerned, some of them have been found to correlate with the presence of esophageal varices. However, none of these parameters (or combination of them) has been proven precise enough to make endoscopy unnecessary ${ }^{(5)}$.

\section{AIM OF THE WORK}

The aim of the current study was to determine the predictive value of noninvasive parameters (Rt. lobe diameter/ serum albumin ratio) in the prediction of esophageal varices.

\section{PATIENTS AND METHODS}

This study included a total of 120 patients divided into four groups attending at outpatient clinics of Tropical Medicine, Al Azhar university Hospitals (El-Hussein and Bab Al-Shariah), Cairo, Egypt. Approval of the ethical committee and a written informed consent from all the subjects were obtained. This study was conducted between August 2017, and July 2018.

\section{Inclusion Criteria:}

1- All patients aged above 18 and below 60-yearsold.

2- All patients have liver cirrhosis except (Group

D) diagnosed by:

a. Abdominal Ultrasound.

b. APRI (AST to Platelet Ratio Index): $2.0=$ cirrhosis ${ }^{(25)}$

3- All Cases have positive serum anti-HCV IgG antibodies except negative controls (Group D).

\section{Exclusion Criteria:}

1. Patients who refused to be enrolled in the study.

2. Patients with previous variceal bleeding.

3. Patients with previous endoscopic variceal sclerosis or band ligation.

4. Patients with previous surgery for portal hypertension and transjugular intrahepatic Portosystemic stent shunt placement

5. Patients received drugs for primary prophylaxis of variceal bleeding (e.g. (b-blockers) or other vasoactive drugs.

6. Patients having sonographic evidence of hepatic focal lesion(s).

7. Bilharzial liver by serum anti-schistosomal IgG antibody.

The patients were grouped according to the results of the upper GIT endoscopy, Abdominal Ultrasound and APRI (AST to Platelet Ratio Index): $2.0=$ cirrhosis $^{(25)}$ into four groups:

Group A: includes 30 cirrhotic patients with OVs grade I to II.

Group B: includes 30 cirrhotic patients with OVs grade III to IV.

Group C: includes 30 cirrhotic patients without OVs.

Group D: includes 30 none cirrhotic patients presented for OGD screening because of other etiologic factors that are not associated with liver cirrhosis.

All participants enrolled in the study were subjected to Full medical history with special stress on: History of liver disease. History of viral hepatitis or other risk factors e.g. blood transfusion, operations... etc. Symptoms of liver cell failure as fatigue, fever, bleeding tendency, itching, yellowish discoloration of sclera, dark coloration of the urine, abdominal distension, swelling of lower limbs, hematemesis, melena and disturbed conscious level. History of hepatic encephalopathy, clinical examination; laboratory investigations (CBC, Liver function tests, prothrombin time and concentration), modified Child-Pugh score and Abdominal ultrasonography 
(studying the right lobe and left lobe diameter, the presence of periportal thickening, the splenic longest axis and the presence of ascites and Portal vein diameter. Right liver lobe diameter/albumin ratio were calculated for all patients. Upper endoscopy was done for detection and grading of esophageal varices.

\section{Statistical analysis}

Data were analyzed using Statistical

Program for Social Science (SPSS) version 15.0. Quantitative data were expressed as mean \pm

\section{RESULTS}

\section{Distribution of patients according to age and sex:}

Table (1): Distribution of patients according to age and sex

\begin{tabular}{|c|c|c|c|c|c|c|}
\hline riables & Group & $\begin{array}{c}\text { Group A } \\
(\mathbf{N}=\mathbf{3 0})\end{array}$ & $\begin{array}{c}\text { Group B } \\
(\mathbf{N}=\mathbf{3 0})\end{array}$ & $\begin{array}{c}\text { Group C } \\
(\mathbf{N}=\mathbf{3 0})\end{array}$ & $\begin{array}{c}\text { Group D } \\
(\mathbf{N}=\mathbf{3 0})\end{array}$ & p-value \\
\hline e (years) & $\begin{array}{l}\text { ean } \\
\text { D }\end{array}$ & $\begin{array}{c}55.3 \\
2.9\end{array}$ & $\begin{array}{c}54.5 \\
2.3\end{array}$ & $\begin{array}{c}55.7 \\
2.4\end{array}$ & $\begin{array}{c}55.3 \\
2.1\end{array}$ & 0.3 \\
\hline $\mathrm{x}$ & $\begin{array}{l}\text { ale } \\
\text { male }\end{array}$ & $\begin{array}{l}15(50 \%) \\
15(50 \%)\end{array}$ & $\begin{array}{l}12(40 \%) \\
18(60 \%)\end{array}$ & $\begin{array}{l}18(60 \%) \\
12(40 \%)\end{array}$ & $\begin{array}{l}16(53 \%) \\
14(47 \%)\end{array}$ & 0.3 \\
\hline
\end{tabular}

Table (1) shows no statistically significant difference between studied groups as regard demographic data (age and gender).

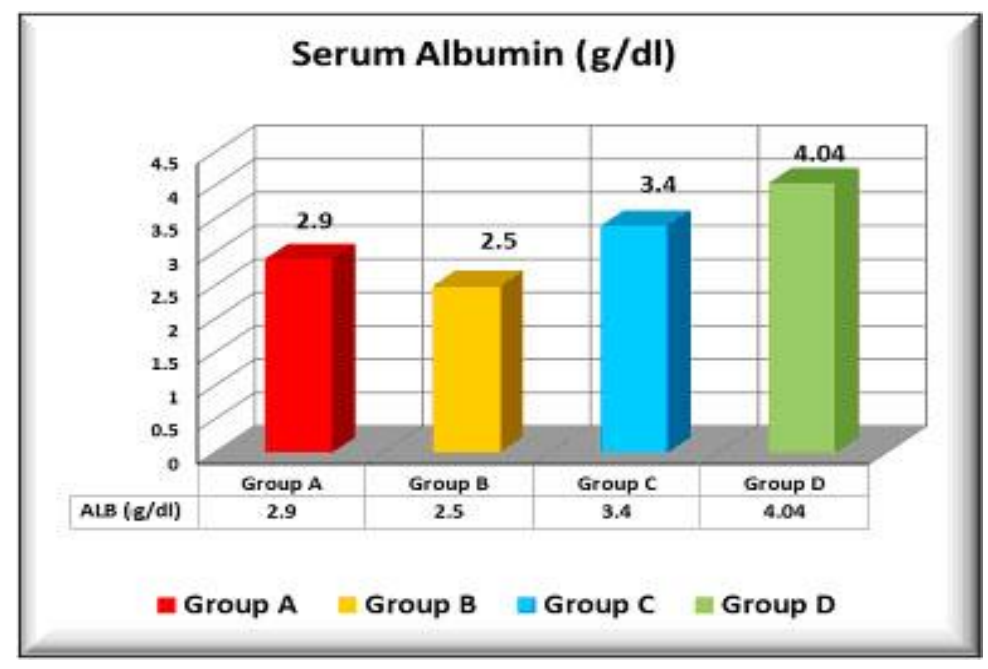

Figure (1): Shows level of serum albumin.

In this study the low level of serum albumin was significantly prevalent in patients with varices $(2.9 \pm 0.41$ versus $4.04 \pm 0.32)$. There was highly statistically significant difference between (A vs B), (A vs $\mathrm{C})$, (A vs D), (B vs C), (B vs D) and (C vs D). 


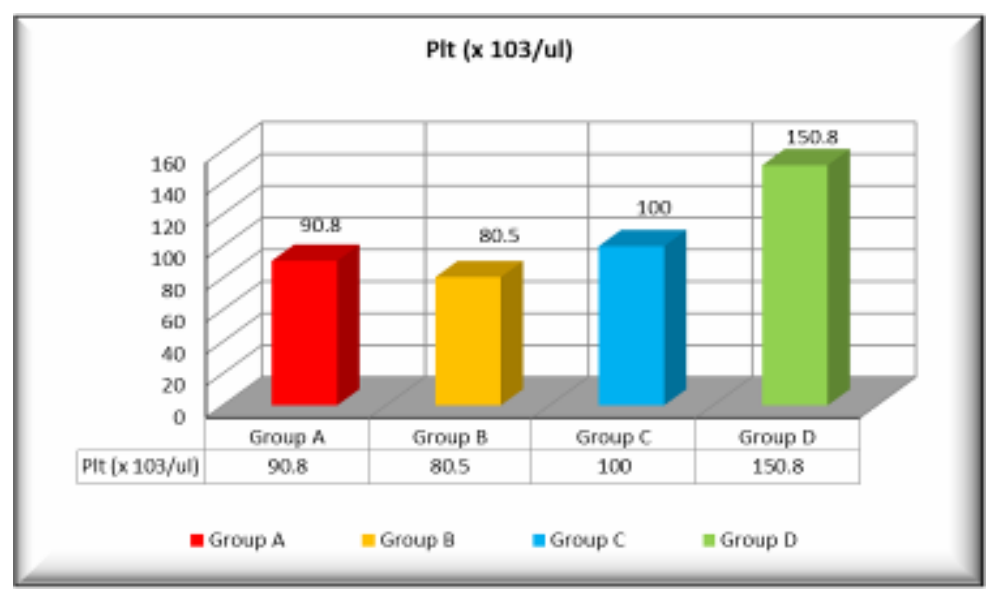

Figure (2): Comparison between studied groups as regard Platelets counts $(=103 / \mu 1)$.

In this study the mean platelets count was significantly lower in the patients with varices, $(90.81 \pm 10.1$ in group $A, 80.5 \pm 9.4$ in group $B$ versus $100.15 \pm 6.3$ in group $C$ and $150.8 \pm 22$ in group $D)$. There was highly statistical significant difference between (A vs D), (B vs C), (B vs D) and (C vs D).

In this study we found that the more advanced the liver disease (according to child class scoring of the patients), the more likely the presence of varices, as expected, esophageal varices and it is grade were significantly more in Child-class $\mathrm{C}$ patients and Child-class B patients compared to Child-class A patients. in group A, 21 patients (70\%) child A with OVs grade I and in group B 18 patients (60\%) child $\mathrm{B}, \mathrm{C}$ has OVs grade III\&IV.

Table (2): Distribution of patients according to child score in cirrhotic patients

\begin{tabular}{|l|c|c|c|c|c|}
\hline \multirow{2}{*}{ riables } & $\begin{array}{c}\text { Group A } \\
(\mathbf{N}=\mathbf{3 0})\end{array}$ & $\begin{array}{c}\text { Group B } \\
(\mathbf{N}=\mathbf{3 0})\end{array}$ & $\begin{array}{c}\text { Group C } \\
(\mathbf{N}=\mathbf{3 0})\end{array}$ & \multirow{2}{*}{ p-value } \\
\cline { 1 - 5 } \multirow{3}{*}{ ild score } & & $24(80 \%)$ & $12(40 \%)$ & $30(100 \%)$ & \multirow{2}{*}{$<0.001 *$} \\
\cline { 2 - 5 } & & $6(20 \%)$ & $15(50 \%)$ & $0(0 \%)$ & \\
\cline { 2 - 5 } & & $0(0 \%)$ & $3(10 \%)$ & $0(0 \%)$ & \\
\hline
\end{tabular}

This table shows highly statistical significant difference between studied groups as regard Child score. In this study we found that patients with shrunken right lobe of the liver had significantly high incidence of varices.

Table (3): Distribution of patients according to Rt. Liver Lobe Diameter

\begin{tabular}{|c|c|c|c|c|c|c|}
\hline riables & Group & $\begin{array}{c}\text { Group A } \\
(\mathbf{N}=\mathbf{3 0})\end{array}$ & $\begin{array}{c}\text { Group B } \\
(\mathbf{N}=\mathbf{3 0})\end{array}$ & $\begin{array}{c}\text { Group C } \\
(\mathbf{N}=\mathbf{3 0})\end{array}$ & $\begin{array}{c}\text { Group D } \\
(\mathbf{N}=\mathbf{3 0})\end{array}$ & p-value \\
\hline \multirow{2}{*}{ Lobe D. } & ean & 12.2 & 11.5 & 13.2 & 14.8 & \multirow{2}{*}{$<0.001 *$} \\
\hline & $\mathbf{D}$ & 0.3 & 0.4 & 0.4 & 1.4 & \\
\hline
\end{tabular}

This table shows highly statistical significant difference between studied groups as right liver lobe diameter. In this study we found that Right liver lobe/S.albumin ratio correlated with presence and grading of esophageal varices, with cutoff value $(4.1 \pm 0.4 \mathrm{SD})$ with OV grade I, $(4.3 \pm 0.7 \mathrm{SD})$ with OV grade III and (4.6 $\pm 0.6 \mathrm{SD})$ with OV grade IV.

Table (4): Distribution of patients according to RLLD/S. ALB ratio

\begin{tabular}{|c|c|c|c|c|c|c|}
\hline \multicolumn{2}{|c|}{$\begin{array}{c}\text { Groups } \\
\text { Variables }\end{array}$} & $\begin{array}{c}\text { Group A } \\
(\mathbf{N = 3 0})\end{array}$ & $\begin{array}{c}\text { Group B } \\
(\mathbf{N}=\mathbf{3 0})\end{array}$ & $\begin{array}{c}\text { Group C } \\
(\mathbf{N}=\mathbf{3 0})\end{array}$ & $\begin{array}{c}\text { Group D } \\
(\mathbf{N}=\mathbf{3 0})\end{array}$ & p-value \\
\cline { 1 - 7 } LD/S. ALB Ratio & Mean & 4.1 & 4.3 & 3.8 & 3.6 & \multirow{2}{*}{$\mathbf{0 . 0 0 1 *}$} \\
\cline { 2 - 7 }
\end{tabular}


The cutoff value of the right lobe diameter $(\mathrm{cm}) /$ Albumin ration was determined at the point of highest sensitivity and specificity, cut off value were (4.1) where sensitivity and specificity were $62 \%$ and $73.3 \%$ respectively.

Table (5): Cut of point of RLLD/S. ALB ratio:

\begin{tabular}{|c|c|c|c|c|c|}
\hline Cut off & Area under the curve & Sensitivity & Specificity & PPV & NPV \\
\hline$>4.1$ & 0.7 & $62 \%$ & $73.3 \%$ & $73.9 \%$ & $59.4 \%$ \\
\hline
\end{tabular}

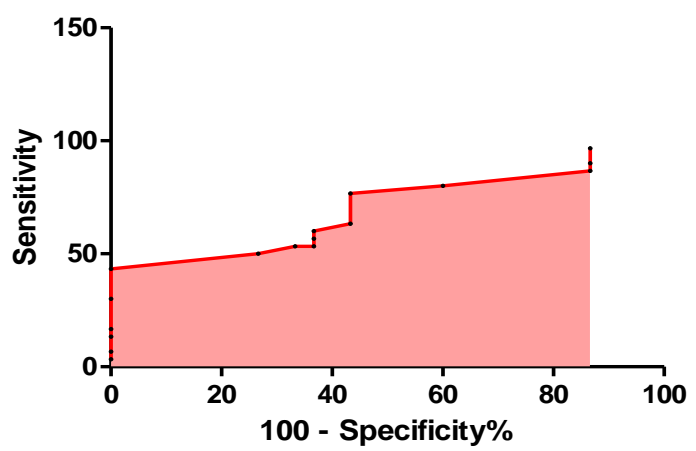

Figure (3): ROC curve of RLLD/S. ALB ratio for prediction of esophageal varices

Receiver operating characteristics (ROC) curve was define the best cut off value of serum ratio which was $>4.1$, area under the curve $=0.7$, with sensitivity of $62 \%$, specificity of $73.3 \%$, positive predictive value of $73.9 \%$ and negative predictive value of $59.4 \%$.

\section{DISCUSSION}

Analysis of data in our study showed that low level of serum albumin was significantly prevalent in patients with varices $\{2.9 \pm 0.41$ versus $4.04 \pm 0.32\}$, Hypoalbuminemia in cirrhosis is multifactorial and may be due to reduced production (liver parenchyma replaced by fibrous tissue), or increased loss through gut (portal gastropathy/enteropathy) all related to portal hypertension ${ }^{(14)}$.

Similar result had been reported in several studies; Schepis et al. (15), on their study conducted on \{One hundred forty-three consecutive cirrhotic patients\} for prediction of esophageal varices found that low serum albumin was more prevalent with patients with esophageal varices $(\mathrm{p}=0.008)$.

Madhotra et al. ${ }^{(16)}$, found that low serum albumin was significantly associated with the presence of esophageal varices with $(\mathrm{P}$ value $=0.001)$.

Hossain et al. ${ }^{(17)}$, in a study which was done on 100 cirrhotic patients for estimation of hypoalbuminemia and its correlation with development of esophageal varices, concluded that hypoalbuminemia is a good surrogate marker for the presence of esophageal varices.

Ayman et al. ${ }^{(18)}$ in their study on 120 Egyptian cirrhotic patients found that low serum albumin is significantly associated with presence of varices $(\mathrm{P}$ value $=0.009)$, same results was found on a study by Adel and George ${ }^{(19)}$.

In this study the mean platelets count was significantly lower in the patients with varices, $\{90.81 \pm 10.1$ in group $\mathrm{A}, 80.5 \pm 9.4$ in group $\mathrm{B}$ versus $100.15 \pm 6.3$ in group $C$ and $150.8 \pm 22$ in group $\mathrm{D}(\mathrm{P}$ value $=0.001)\}$.

This result is agreed by the results of Hesham et al. ${ }^{(20)}$ and Serag et al. ${ }^{(21)}$.

Serag et al. ${ }^{(21)}$ found that platelet count at cut off value $131 \times 10^{3}$ is a good predictor and showed significant correlation for presence of esophageal varices.

In this study we found that the more advanced the liver disease (according to child class scoring of the patients), the more likely the presence of varices, as expected, esophageal varices and it is grade were significantly more in Child-class $\mathrm{C}$ patients and Child-class B patients compared to Child-class $A$ patients. in group A, 21 patients $(70 \%)$ child A with OVs grade I and in group B 18 patients $(60 \%)$ child B,C has OVs grade III\&IV with $P$ value $=0.0001$. 
Burton et al. (22) showed that the incidence of esophageal varices increases with worsening Child-Pugh class and raised a predictive model relying on thrombocytopenia and Child-Pugh class. Burton's model revealed that patients with platelet count less than $90,000 / \mathrm{mm}$ will have a probability of $0.57,0.81$ and 0.82 of having any varices, if they are in Child A, B, or C classes, respectively.

Serag et al. ${ }^{(21)}$ found that advanced Child class (Child class B\&C) showed statistically significant correlation with the presence of esophageal varices, Ayman et al. ${ }^{(18)}$ reported that patients with Child class B and C had higher incidence of esophageal varices compared to Child A patients $(39.8 \%, 43.4 \%, 16.8 \%)$ respectively with $\mathrm{p}$ value $=0.004$.

In this study we found highly statistical significant difference ( $\mathrm{p}$-value $<0.001)$ between studied groups as regard Apri score.

In this study we found that patients with shrunken right lobe of the liver had significantly high incidence of varices $(\mathrm{P}=0.0001)$.

Sharma and Aggarwal ${ }^{(13)}$, found that shrunken liver correlated significantly with the presence of varices ( $\mathrm{P}=0.02)$, Same result reported by Serag $\boldsymbol{e t}$ al. ${ }^{(24)}$ who found significant difference in the live size between the patient with varices and those without varices $(\mathrm{P}=0.03)$.

The application of the right liver lobe diameter/albumin ratio as a predictor of esophageal varices was first proposed by Alempijevic et al. ${ }^{(23)}$ in a study of 94 cirrhotic patients, he found that Right liver lobe/albumin ratio correlated with presence of esophageal varices, We found statistical significant difference between the right liver lobe diameter(mm)/albumin ratio in the patient with varices and those without varices $47.5 \pm 17.4$ versus $35.9 \pm 13.5$ ( $\mathrm{p}$ value $=0.005$ ), the same results were obtained by Hesham et al. ${ }^{(20)}$, Serag and Dalia $^{(24)}$, and Adel and George ${ }^{(19)}$.

A receiver operator characteristic (ROC) curve was constructed and the area under the ROC curve (AUROC) was calculated. The cutoff value of the right lobe diameter $(\mathrm{cm}) /$ Albumin ration was determined at the point of highest sensitivity and specificity, cut off value were (4.1) where sensitivity and specificity were $50 \%$ and $73.3 \%$ respectively, the area under curve (AUC) is $0.7 \%$ and positive predictive value of $73.9 \%$ which has good prediction power for presence of esophageal varices.

\section{CONCLUSION}

The right liver lobe diameter/s. albumin ratio might be considered a significant predictor for the presence and grading of esophageal varices. Thrombocytopenia, splenomegaly, advanced liver disease (worsen child score) and decreased right lobe diameter, were significantly associated with the presence of varices.

\section{REFERENCES}

1- Neil R and David AG (2013): Endoscopic Management of Oesophageal and Gastric Varices, Endoscopy of GI Tract, Edited by Somchai Amornyotin.

2- Garcia-Tsao G and Bosch J (2010): Management of varices and variceal hemorrhage in cirrhosis. N. Engl. J. Med., 362(9): 823-832.

3- Garcia-Tsao G, Friedman $\mathrm{S}$, Iredale J et al. (2010): Now there are many (stages) where before there was one: In search of a pathophysiological classification of cirrhosis. Hepatology, 51: 14451449.

4- De Franchis $\mathbf{R}$ (2010): Revising consensus in portal hypertension: report of the Baveno $\mathrm{V}$ consensus workshop on methodology of diagnosis and therapy in portal hypertension. J. Hepatol., 53:762-768.

5- D'Amico G, Garcia-Tsao G, Calés $P$ et al. (2001): Diagnosis of portal hypertension: how and when. In: De Franchis R, ed. Proceedings of the Third Baveno International Consensus Workshop on Definitions, Methodology and Therapeutic Strategies. Oxford: Blackwell Science, 36-63.

6- D'Amico G and Morabito A (2004): Non invasive markers of oesophageal varices: another round.not the last, Hepatol., 39:30-34.

7- Thomopoulos K, Labropoulou K, Mimidis K et al. (2003): Non- Invasive predictors of the presence of large esophageal varices in patients with cirrhosis. Dig and Liver Dis., 35: 473-478.

8- McGuire BM (2001): Safety of endoscopy in patients with end-stage liver disease. Gastrointest Endosc Clin N Am., 11(1):111-30. 
9- Almeida D, Lopes AA, Santos-Jesus R et al. (2001): Comparative study of bacterial infection prevalence between cirrhotic patients with and without upper gastrointestinal bleeding. Braz $\mathrm{J}$ Infect Dis., 5(3):136-42.

10- Kim BK, Han KH, Park JY et al. (2010): A liver stiffness measurementbased, noninvasive prediction model for high-risk esophageal varices in Bviral liver cirrhosis. Am $\mathbf{J}$ Gastroenterol., 105:1382-1390.

11-

Sebastiani G, Tempesta D, Fattovich

G et al. (2010): Prediction of oesophageal varices in hepatic cirrhosis by simple serum non-invasive markers: results of a multicenter, large-scale study. J Hepatol., 53:630-638.

12- $\quad$ Angelo Zambam de Mattos, Angelo Alves de Mattos, Larissa Faraco Daros et al. (2013): Non invasive prediction of oesophageal varices. Annals of Hepatology, 12 (5): 810-814.

13- $\quad$ Sharma SK and Aggarwal R (2007): Prediction of large esophageal varices in patients with cirrhosis of the liver using clinical, laboratory and imaging parameters. Journal of Gastroenterology and Hepatology, 22: 19091915.

14- Torres E, Barros P, Calmet F (1998): Correlation between serumascites albumin concentration gradient and endoscopic parameters of portal hypertension. Am J Gastroenterol., 93:2172-8.

15-Schepis F, Camma C, Niceforo D et al. (2001): Which patients with cirrhosis should undergo endoscopic screening for esophageal varices detection?. Hepatology, 33(2): 333-338.

16- Madhotra R, Mulcahy HE, Willner I et al. (2002): Prediction of esophagealvarices in patients with cirrhosis. J Clin Gastroenterol., 34:81-85.

17- Hossain SF, Islam QT, Siddiqui MR et al. (2011): A Study of Hypoalbuminaemia in Chronic Liver Disease and its Correlation with Development of Esophageal Varices, Bangladesh J Medicine, 22: 17-20.

18- $\quad$ Ayman Y, Rbab F, Mohamad AB et al. (2009): Non Invasive Prediction of Varices in Egyptian Cirrhotic Patients, Med. J. Cairo Univ., 77(1): 343-349.
19- $\quad$ Adel AM and George SR (2011): A novel non-invasive Ratio for oesophageal varices prediction in HCV- liver cirrhosis Egyptian patients. Journal of American Science, 7(11):3336.

20-

Hesham Ezz Eldin S, Engy YE, Aml A et al. (2010): Cytopenia As A Predictor Of Oesophageal Varices In Patients With Liver Cirrhosis, Report and Opinion, 2(7)66-69.

21-Serag E, Dalia O and Laila R (2012): Can we consider the right hepatic lobe size/albumin ratio a noninvasive predictor of oesophageal varices in hepatitis $\mathrm{C}$ virus-related liver cirrhotic Egyptian patients?, European Journal of Internal Medicine, 23: $267-272$

22- Burton JR, Liangpunsakul S, Lapidus J et al. (2007): Validation of a multivariate model predicting presence and size of varices, Journal of Clinical Gastroenterology, 41(6): 609-615.

23- $\quad$ Alempijevic T, Bulat V, Djuranovic S et al. (2007): Right liver lobe/albumin ratio: contribution to non-invasive assessment of portal hypertension, World Journal of Gastroenterology, 13(40): 5331- 5335.

24- $\quad$ Serag E and Dalia O (2011): Study of Noninvasive Predictors of Portal Hypertension in Liver Cirrhotic Egyptian Patients, Journal of American Science, 7(1):99-104.

25- $\quad$ Sharma S, Khalili K, Nguyen GC et al. (2014): Non-invasive diagnosis of advanced fibrosis and cirrhosis. World J Gastroenterol., 20(45): 16820-16830.

26- $\quad$ Everitt BS (2006): The Cambridge Dictionary of Statistics, 3rd edn, Cambridge University Press. 